\section{Facilitation of olfactory detection*}

\author{
TIINA E. CORBIT $†$ and TRYGG ENGEN \\ Brown University, Providence, Rhode Island 02912
}

Olfactory sensitivity to $n$-aliphatic alcohols was determined by use of a yes-no signal detection procedure. The values of $\mathrm{d}^{\prime}$ for these compounds indicated higher sensitivity and less variability than has been shown previously by classical threshold methods. Self- and cross-adaptation studies demonstrated the usual decrement in sensitivity to one stimulus, following exposure to another stimulus, and in addition, cross-facilitation with certain stimulus pairings. The facilitating effects of one odorant upon the detection of another may be related to the differences in water solubilities of the odorants.

Cross-adaptation has been used to study the classification of olfactory stimuli (Le Magnen, 1942-43; Moncrieff, 1956; Cheesman \& Townsend, 1956; Engen, 1963). In the cross-adaptation experiment, olfactory stimuli are presented in pairs, and the effect of exposure to the first (adapting) stimulus on sensitivity to the second (test) stimulus is determined. The underlying assumptions of the cross-adaptation experiment are that: olfactory stimuli are similar to the extent that they activate the same receptor types; the adapting stimulus leaves the receptors it activates in a refractory state, unavailable to the test stimulus; the decrease in sensitivity to the test stimulus reflects the degree of overlap in the specificity of action of the two stimuli, and hence, the degree of their subjective similarity. In general, previous cross-adaptation studies have demonstrated that decreases in sensitivity to the test stimulus are greater with odorant pairs which are judged similar than with pairs which are judged dissimilar (e.g., Moncrieff, 1956).

At the beginning of this study, research already underway by Engen and Bosack (1969) with human infants showed that systematic adaptation effects could be demonstrated within the homologous linear alcohols, and that certain pairings of stimuli even resulted in increased sensitivity or cross-facilitation. The present study was designed to extend this work to adult $O s$ and to verify the existence of cross-facilitation. A signal detection procedure was considered necessary for this purpose in order to obtain a measure of the response criterion. Since the presentation of an adapting stimulus may raise the criterion for

*This research was supported by Grant HD-02358-02 from the United States Public Health Service to Trygg Engen. William S. Cain made helpful comments on the manuscript.

+Requests for reprints should be sent to Tiina E. Corbit, Walter $S$. Hunter Laboratory of Psychology, Brown University, Providence, Rhode Island 02912 calling a test stimulus odorous independently of any changes in sensitivity, it is especially important to control this source of variability in the $O$ 's response in cross-adaptation experiments.

\section{EXPERIMENT 1}

The first experiment was designed to establish subjectively equal intensities of three odorants, using the yes-no signal detection procedure (Green \& Swets, 1966). This procedure involves the presentation of a series of trials on which the $O$ must decide whether only background noise (N) or a signal plus noise (SN) is present. In the present experiment, the signal consisted of odorous air added to a pure airstream, which may be considered as a background of noise. In addition to this noise introduced by the $\mathrm{E}$, it is assumed that noise is inherent in the sensory process (Swets, Tanner, \& Birdsall, 1964).

\section{Method}

Observers. Three female undergraduates served as Ss. None of them smoked.

Apparatus. An air-dilution olfactometer with two identical but independent channels was used for presenting and controlling the stimuli. ${ }^{1}$ One channel was used for presenting the adapting stimuli and the other for presenting the test stimuli. Each had a Teflon delivery tube (1.5-in. diam) mounted on the front wall of the experimental chamber. Both channels contained two separate air lines, one for pure odorless air and one for saturated odorous air, with the desired stimulus concentration obtained by mixing air from the two lines in various proportions. Flow in each line was measured by Fisher-Porter flowmeters. Air from each channel was diverted either to the $O$ 's chamber (during a trial) or to an exhaust vent. On noise trials, air from the saturated odor line in the test channel flowed directly to exhaust, bypassing the final common path. The flowrate in the final paths of each channel was always $2,000 \mathrm{ml} / \mathrm{min}$.
Saturation was accomplished by flowing air through two Fisher-Milligan gas washer bottles containing the undiluted odorant. Tests of the weight of odorant lost when a known volume of air was flowed through the bottles confirmed that saturation was complete. The bottles of odorant and $25 \mathrm{ft}$ of copper tubing in each pure air line were set in a water bath maintained at $20^{\circ} \pm 1^{\circ} \mathrm{C}$. Between odorants, all parts of the system which fed odorous air to the pure airstream were removed and thoroughly cleaned.

The experiments were run in an air-conditioned room $\left(70^{\circ} \pm 1^{\circ} \mathrm{F}\right)$ with a relative humidity of $50 \%-60 \%$. The 0 sat in a Formica-lined booth with exhaust fans for removing the odorous air located on the top and on one side of the booth.

Presentation of the stimuli was controlled by a series of relays and timers. A system of switches, indicator lights, and counters was used for registering and recording responses. The $O$ had two buttons for signaling his decisions. Correct and incorrect decisions turned on different indicator lights, providing the $\mathrm{O}$ with immediate feedback. Counters kept a running tally of correct and incorrect responses. The E's panel had similar indicator lights and two counters which recorded hits and false alarms.

Three odorants from the linear homologous alcohols were used: n-propyl alcohol $\left(C_{3}\right)$, n-butyl alcohol $\left(\mathrm{C}_{4}\right)$, and $n$-heptyl alcohol $\left(\mathrm{C}_{7}\right)$. They were reagent grade and obtained from Fisher Scientific Company.

Procedure. Daily sessions of 100 trials were run at approximately the same time each day. Each trial consisted of either odorous air mixed with pure air (SN) or pure air (N), and the O's task was to decide between these two alternatives on each presentation. Presentation schedules were derived from random number tables with the restrictions that no more than four of one kind of trial could occur in sequence and that $.48 \leqslant \mathrm{p}(\mathrm{SN}) \leqslant .52$. A different schedule was used for each session and for each 0 . Os were told that there would be approximately the same number of each kind of trial.

Each trial consisted of the following sequence of events: the Os took one sniff at the output tube of the adaptation channel (the purpose of this is discussed in Experiment 2), then took one sniff from the test channel delivery tube, responded, and sat back until the next trial. Each stimulus was presented for $2 \frac{1}{2} \mathrm{sec}$, followed by a 15 -sec rest interval. The $O$ was instructed to sniff in the same manner on all trials.

Each $O$ was given nine training 
Table 1

Concentrations of Odorous Stimuli in Milligrams Per Liter and Corresponding $\mathbf{d}^{\prime}$ Values for Each $\mathbf{O}$

\begin{tabular}{|c|c|c|c|c|c|c|}
\hline & \multicolumn{2}{|c|}{01} & \multicolumn{2}{|c|}{02} & \multicolumn{2}{|c|}{ O 3} \\
\hline & $\begin{array}{c}\text { Concen- } \\
\text { tration }\end{array}$ & $d^{\prime}$ & $\begin{array}{c}\text { Concen- } \\
\text { tration }\end{array}$ & $d^{\prime}$ & $\begin{array}{l}\text { Concen- } \\
\text { tration }\end{array}$ & $\mathrm{d}^{\prime}$ \\
\hline n-propyl alcohol & .046 & 1.44 & .051 & 1.38 & .051 & 1.44 \\
\hline n-butyl alcohol & .013 & 1.56 & .013 & 1.38 & .020 & 1.38 \\
\hline n-heptyl alcohol & .001 & 1.40 & .001 & 1.16 & .001 & 1.24 \\
\hline
\end{tabular}

sessions, three sessions with each odorant. The purpose of these sessions was to stabilize performance, and to allow the $E$ to determine the concentrations for each odorant that produced approximately $75 \%$ correct responses (i.e., concentrations corresponding to a $d^{\prime}$ of approximately 1.35 ). It was important to obtain concentrations which would allow maximum variation in response in Experiment 2, that is, halfway between chance and perfect detection. During training sessions, the stimulus concentration was gradually decreased until detection appeared stable at one stimulus concentration. For these sessions Os were paid $\$ 1.50$ per session. Three additional training sessions were then given for which Os were awarded 3 cents for each correct response (hits and correct rejections) and fined 3 cents for each incorrect response (false alarms and misses). Performance improved slightly when the payoff matrix was introduced, and stimulus concentrations were lowered slightly to maintain approximately $75 \%$ correct responses.

After training, each $\mathrm{O}$ served in $\mathbf{1 5}$ sessions, 5 sessions each for $\mathrm{C}_{3}, \mathrm{C}_{4}$, and $C_{7}$. Two of these sessions for each odorant were run at the end of Experiment 2 to be sure that sensitivity had not changed over the course of the experiments. It was necessary that all Os receive the three odorants in the same order since only one odorant could be used in the olfactometer on any given day. Sessions were run daily, with only an occasional day omitted. All five sessions for one odorant were run with the concentration that yielded

Table 2

Order of Presentation of the Adaptation Conditions

\begin{tabular}{ccc}
$\begin{array}{c}\text { Condition } \\
\text { Number }\end{array}$ & $\begin{array}{c}\text { Adapting } \\
\text { Stimulus }\end{array}$ & $\begin{array}{c}\text { Test } \\
\text { Stimulus }\end{array}$ \\
\hline 1 & $\mathrm{C}_{7}$ & $\mathrm{C}_{3}$ \\
2 & $\mathrm{C}_{3}$ & $\mathrm{C}_{3}$ \\
3 & $\mathrm{C}_{4}$ & $\mathrm{C}_{3}$ \\
4 & $\mathrm{C}_{4}$ & $\mathrm{C}_{4}$ \\
5 & $\mathrm{C}_{7}$ & $\mathrm{C}_{4}$ \\
6 & $\mathrm{C}_{3}$ & $\mathrm{C}_{4}$ \\
7 & $\mathrm{C}_{3}$ & $\mathrm{C}_{7}$ \\
8 & $\mathrm{C}_{4}$ & $\mathrm{C}_{7}$ \\
9 & $\mathrm{C}_{7}$ & $\mathrm{C}_{7}$ \\
\hline
\end{tabular}

approximately $75 \%$ detection in the training sessions. At the beginning of each session the $O$ was given an example of each kind of trial to reacquaint her with the odorant.

It was important in the present experiment to be sure that there were no extraneous cues available to the $O$ on which to base her decision. As a control for possible extraneous cues, one of the Os who had had previous experience in olfactory detection experiments was run in four 100-trial sessions with no odorant in the system. On one half of the trials, $3.125 \%$ of the channel output came from the "odorous" line, although in this case the line contained no odorant. These trials were called "SN" trials. On the remaining trials, air was presented only from the pure air line, and these were called " $N$ " trials. In all other respects the procedure was identical to the actual experiment.

\section{Results}

The number of hits and the number of false alarms were transformed into probability values and the value of $d^{\prime}$ was obtained from a table (Elliott, 1964) listing $d^{\prime}$ as a function of these two probabilities for the yes-no procedure. The $d^{\prime}$ vallues obtained for the $O$ run in the control experiment where no odorant was used were around zero (ranging from -0.36 to $+0.26)$ and indicate that the equipment did not provide any extraneous cues.

$d^{\prime}$ values based on 500 trials were then determined for each odorant, and these $d^{\prime}$ vallues and the corresponding concentrations of the odorants are presented in Table 1. It may be seen that as chain length increases, the concentration required to produce approximately the same value of $d^{\prime}$ progressively decreases.

\section{EXPERIMENT 2}

The second experiment was designed to study the effects of self-adaptation and cross-adaptation on the detection of linear homologous alcohols, using low intensity adapting stimuli of equal subjective intensity obtained from Experiment 1.

\section{Method}

Observers. The same three Os were used in this experim $n^{\dagger}$. They were paid for training sessions and test session according to the rates used in Experiment 1.

Procedure. The apparatus is decribed in Experiment 1.

Experiment 2 consisted of the nine conditions of adaptation shown in Table 2. Each odorant was used as an adapting stimulus for itself (self-adaptation) and for each of the other two odorants (cross-adaptation). Each $O$ served in all of the conditions and in the order shown, because only one odorant could be used in one channel per day.

Three 100-trial sessions were run in each condition. Exactly the same procedure was followed as in Experiment 1, with the exception that an adapting stimulus was now presented from the first output tube on each trial. The adapting stimulus always consisted of odorous air, and the test stimulus, as in Experiment 1, contained odorous air with $p \sim \mathbf{. 5 0}$ and pure air with $p \sim .50$. The concentrations of all of the stimuli are those shown in Table 1. Thus, the procedure for each trial was as follows: the $O$ took one sniff of the adapting stimulus from the right-hand output tube, moved her head over to the left-hand output tube while exhaling, took one sniff of the test stimulus, made her response, and sat back for the rest interval. The duration of one exhalation (2-3 sec) was chosen as the interstimulus interval; thus the interval was kept as short as possible while still allowing the $O$ to breathe naturally. Both the adapting stimulus and the test stimulus were presented for $2 \frac{1}{2} \mathrm{sec}$. The rest interval was 15 sec. The $O$ was instructed to sniff in the same manner at each tube but to concentrate only on the test stimulus in making her decision.

Note that during Experiment 1 the

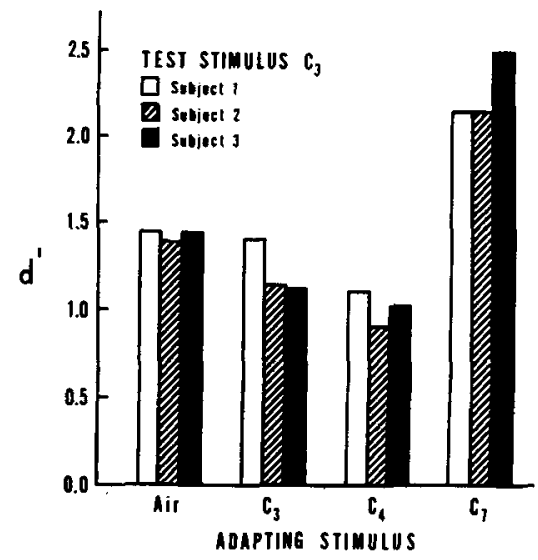

Fig. 1. $d^{\prime}$ values obtained for detection of $C_{3}$ by each $S$ under each adaptation condition. 


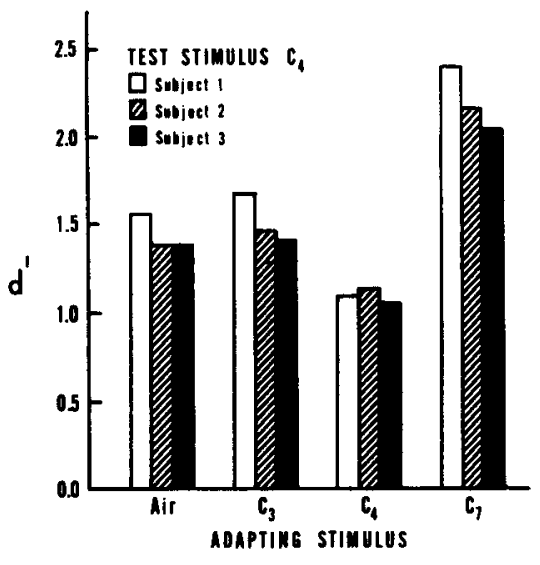

Fig. 2. $d^{\prime}$ values obtained for detection of $\mathrm{C}_{4}$ by each $\mathrm{S}$ under each adaptation condition.

$O$ sniffed room air at the first delivery tube so that the procedure was as nearly identical to the adaptation sessions of Experiment 2 as possible. Pure air was not presented from the first tube in Experiment 1 because it was not desirable for the $O$ to have a standard of "noise" against which to compare each test trial. Such a standard might improve detection and would not be available during adaptation sessions.

In Experiment 2 there was a transitory decrement in performance in all Os with the introduction of an adapting stimulus. In some cases, performance fell to chance, and it was necessary to increase the concentration of the test stimulus before the $O$ could detect it. This concentration was then gradually lowered again to the concentration used in the experiment proper (Table 1). Each $O$ was given a minimum of seven training sessions with different pairs of odorants until performance on the first and second sets of 50 trials of a session was comparable for at least two sessions.

\section{Results}

Values of $d^{\prime}$ were calculated for the test stimulus in each condition from the proportion of hits and false alarms made in 300 trials. Figure 1 shows the $d^{\prime}$ values obtained for $C_{3}$ in each condition. The $d^{\prime}$ vallues for $C_{3}$ with no adapting stimulus, obtained in Experiment 1, are also presented as baselines against which the effects of the adapting stimuli can be observed. Figures 2 and 3 present data for $\mathrm{C}_{4}$ and $\mathrm{C}_{7}$, respectively, as the test stimuli.

The most prominent effect is facilitation of the detection of $\mathrm{C}_{3}$ and $\mathrm{C}_{4}$ by $\mathrm{C}_{7}$. The usual adaptation effects, described in the introduction, which are predicted on the basis of similarity of odorants, are also evident, although they are smaller and less consistent across Os. $\mathrm{C}_{4}$ appears to have the strongest adapting effect and decreases the detection of both $\mathrm{C}_{4}$ and $\mathrm{C}_{3}, \mathrm{C}_{3}$ shows some self-adaptation in Os 2 and 3 , but the detection of $\mathrm{C}_{7}$ appears to remain relatively constant over all adaptation conditions when all Os are considered.

\section{DISCUSSION}

Experiment 1 supports previous findings that the detection threshold decreases as a homologous series is ascended (Engen, 1965; Moulton \& Eayrs, 1960). However, the present detection procedure apparently provides much lower detection concentrations than those obtained with classical methods in otherwise similar experiments with the same odorants. For example, Jones (1955) obtained $50 \%$ detection threshold concentrations of $4.5 \times 10^{-5}$ and $1.69 \times 10^{-5}$ in terms of molar ratio for $\mathrm{C}_{3}$ and $\mathrm{C}_{4}$, respectively. Molar ratios from Experiment 1 range from $1.72 \times 10^{-5}$ to $1.90 \times 10^{-5}$, and $0.39 \times 10^{-5}$ to $0.60 \times 10^{-5}$, respectively. In addition, the excellent agreement between the present three Os suggests that interinuividual variability is much less than that observed by Jones.

Experiment 2 clearly demonstrates facilitation of detection. When $\mathrm{C}_{7}$ was presented as an adapting stimulus for either $\mathrm{C}_{3}$ or $\mathrm{C}_{4}$, detection of these odorants was enhanced. Engen and Bosack (1969) have demonstrated similar facilitory effects with infants. They found that adaptation to $C_{8}$ (n-octyl alcohol) facilitated detection of $\mathrm{C}_{2}$ and $\mathrm{C}_{3}$ to approximately comparable degrees and slightly decreased detection of $\mathrm{C}_{4}$ and $\mathrm{C}_{7}$. They also showed that $\mathrm{C}_{6}$ facilitated detection of $\mathrm{C}_{3}$ but had no appreciable effect on $\mathrm{C}_{4}$ and slightly decreased detection of $\mathrm{C}_{5}$. However, mixtures of $\mathrm{C}_{3}$ and $\mathrm{C}_{8}$ and of $\mathrm{C}_{3}$ and $\mathrm{C}_{6}$, for example, were not more easily detected than any one of these odorants presented alone. Thus, facilitation appears to depend on the appropriate temporal pairing of longand short-chain homologous alcohols.

One possible explanation for these facilitory effects rests on the fact that the water solubility of homologous compounds decreases with increasing carbon chain length. For example, $\mathrm{C}_{3}$ is infinitely soluble in water while $C_{7}$ is relatively insoluble in water. The olfactory receptors are covered by a watery mucus layer (Reese, 1965) and thus molecules which are minimally soluble in water might penetrate the mucus layer more slowly and be present at the sensory epithelium for a longer period of time than molecules

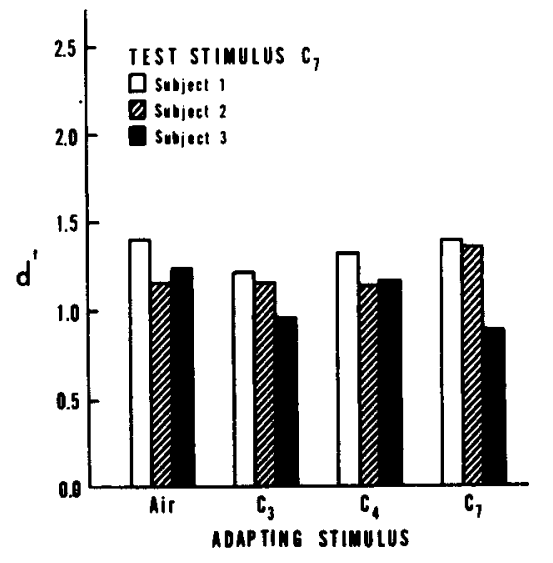

Fig. 3. d' values obtained for detection of $C_{7}$ by each $S$ under each adaptation condition.

which are highly soluble in water and may pass back and forth through the mucus quickly. Slow potential changes in the olfactory mucosa of the frog (Ottoson, 1956) and potentials in the olfactory bulb of the rabbit (Adrian, 1951) have a rapid onset and fast decay in response to relatively water-soluble compounds, and develop and decay more slowly in response to relatively oil-soluble compounds. Ottoson has attributed the differences in rise time to possible differences in the rates at which different molecules reach and activate the receptors. It has also been demonstrated that water solubility is correlated with the slope of the psychophysical function for different odorants (Cain, 1969). This might reflect that water solubility limits the proportion of molecules of an odorant that penetrate the mucus to reach the receptors, and would be in accord with a relationship between water solubility and diffusion rate.

Cross-facilitation has been obtained only when the adapting stimulus is a long-chain compound, with relatively low water solubility, and the test stimulus a short-chain compound, highly soluble in water. Such facilitation may result, then, because the test stimulus penetrates the mucus layer before the adapting stimulus has been completely dissipated. Such an overlap in the time course of the test and adapting stimuli would increase the number of molecules at the receptor surface during the test interval, increasing the probability of exciting a number of receptors sufficient for detection.

\section{REFERENCES}

ADRIAN, E. D. Olfactory discrimination. L'Année Psychologique, 1951, 50, 107-113.

CAIN, W. S. Odor Intensity: Differences in the exponent of the psychophysical function. Perception \& Psychophysics, $1969,6,349-354$. 
CHEESMAN, G. H., \& TOWNSEND, M. J。 Further experiments on the olfactory thresholds of pure chemical substances, using the "sniff-bottle method." Quarterly Journal of Experimental Psychology, 1956, 8, 8-14.

ELLIOTT, P. B. Tables of $d^{\prime}$. In J. A. Swets (Ed.), Signal detection and recognition by human observers: Contemporary readings. New York: Wiley, 1964. Pp. 651-684.

ENGEN, T. Cross-adaptation to the aliphatic alcohols. American Journal of Psychology, 1963, 76, 96-102.

ENGEN, T. Psychophysical analysis of the odor intensity of homologous alcohols. Journal of Experimental Psychology, $1965,70,611-616$.

ENGEN, T., \& BOSACK, T. N. Facilitation in olfactory detection. Journal of
Comparative \& Physiological Psychology, $1969,68,320-326$.

GREEN, D. M., \& SWETS, J. A. Signa detection theory and psychophysics. New York: Wiley, 1966.

JONES, F. N. Olfactory absolute thresholds and their implications for the nature of the receptor process. Journal of Psychology, 1955, 40, 223-227.

Le MAGNEN, J. Étude d'une methode d'analyse qualitative de l'olfaction. L'Année Psychologique, 1942-43, 43-44, 249-264.

MONCRIEFF, R. W. Olfactory adaptation and odor likeness. Journal of Physiology, 1956, 133, 301-316.

MOULTON, D. G., \& EAYRS, J. T. Studies in olfactory acuity. II. Relative detectability of $n$-aliphatic alcohols by the rat. Quarterly Journal of
Experimental Psychology, 1960, 12. 99-109.

OTTOSON, D. Analysis of the electrical activity of the olfactory epithelium. Acta Physiologica Scandinavica, 1956, 5, Supplement 122, 7-83.

REESE, T. S, Olfactory cilia in the frog. Journal of Cellular Biology, 1965, 25, 209-230.

SWETS, J. A., TANNER, W. P., \& BIRDSALL, T. G. Decision processes in perception. In J. A. Swets (Ed.), Signal detection and recognition by human observers: Contemporary readings. New York: Wiley, 1964. Pp. 3-57.

$$
\text { NOTE }
$$

1. For a more detailed description of the olfactometer consult Cain (1969).

(Accepted for publication May 19, 1971.) 